\section{Responsiveness and minimally important difference of a generic quality of life measure for complementary health practices}

\author{
Tomoaki Kimura,1 Kiyoshi Suzuki,1 \\ Seiya Uchida, ${ }^{1}$ Hiroshi Katamura ${ }^{2}$ \\ 1MOA - Health \\ Science Foundation, Shizuoka; \\ 2Gyokusenkai MOA Takanawa Clinic, \\ Tokyo, Japan
}

\section{Abstract}

Shorter and easier methods of conducting community health surveys would be useful. We conducted a study to demonstrate the responsiveness of the 10-item Mokichi Okada Association quality of life questionnaire (MQL-10) in a follow-up survey and to determine the minimally important difference (MID) for this measure. In 2007, Japanese adults participated in a survey on health practices. We analyzed the MQL-10 scores ( $n=6365)$ together with the following factors: gender, age group, disease, reason for participation, and complementary health practices, such as food and eating. The mean baseline MQL-10 score was $26.4 \pm 5.83$ [ standard deviation (SD)] and the mean follow-up score was $27.6 \pm 5.45$ SD with a mean change of $1.20 \pm 4.41 \mathrm{SD}$. The effect size for change was 0.21 and the standardized response mean was 0.27 . The MQL-10 scores in the baseline condition were associated with gender, age group, disease, reason for participation and complementary health practices. Furthermore, the changes in the MQL-10 during the 12 weeks of study were associated with age group, disease, reason for participation and complementary health practices. The increase in frequency of health practices was significantly associated with improvements in the participants' quality of life (QOL). These results suggest that the MQL-10 is useful for assessing the effects of complementary health practices on QOL. The estimate of 3 points for the range of this measure (0-40) was higher than half of the SD of scores; therefore, it was considered reasonable for the MID.

\section{Introduction}

Quality of life (QOL) has received growing attention in health practices and health sta- tus is considered an important QOL component. Seven of Breslow's health practices are well known as part of a lifestyle program for preventing diseases: i) never smoking cigarettes; ii) engaging in regular physical activity; iii) using alcohol moderately or not at all; iv) regularly getting 7-8 h of sleep; v) maintaining an ideal body weight; vi) eating breakfast; and vii) not eating between meals. ${ }^{1}$ In addition to these seven practices, original programs for health have been launched by the Mokichi Okada Association International (MOA) to help citizens prevent diseases, improve QOL, and promote health. The programs are based on the philosophy and work of Mokichi Okada (1882-1955), a Japanese philosopher. ${ }^{2}$ The programs consist of three complementary health practices: i) food and eating; ii) art and culture; and iii) biofield therapy. Although these have come into fairly wide use in Japan and other countries, there is little reported evidence of their impact on improving of QOL or symptoms. Some studies have recently been reported on the use of a type of biofield therapy called Okada Purifying Therapy, used for menopausal symptoms in Japanese women, ${ }^{3}$ for refractory migraine in Italian patients, ${ }^{4}$ and for electroencephalogram effects. ${ }^{5}$

A large number of measures to assess Q0L have been developed, and the short version of the World Health Organization Quality of Life instrument (WHOQOL-BREF, 26 items) ${ }^{6}$ and the 36-Item Short Form Health Survey (SF36) are among those used globally.7 In a community health survey, however, use of other questionnaires as well as a QOL measure becomes a burden for participants. Therefore, a shorter and easier instrument of QOL needs to be developed. The 10-item MOA Quality of Life Questionnaire (MQL-10) has been developed to assess QOL and determine the effects of health practices in large-scale health surveys. ${ }^{8}$ Since the MQL-10 has established validity through comparisons with the WHOQOL-BREF and the SF-36, it is expected to come into general use. Follow-up surveys with longitudinal design need responsiveness to be established as well as the validity of the measure.

In large-scale surveys, even subtle differences or changes can result in statistical significance. It is essential to discuss whether differences between groups or changes within groups are clinically important. Therefore, the minimally important difference (MID) of a measure needs to be investigated for use in a longitudinal setting. MIDs of several instruments have already been established. ${ }^{9-13}$ This study was conducted to demonstrate the responsiveness of the MQL-10 in a follow-up survey on complementary health practices and to determine the MID for this instrument.
Correspondence: Tomoaki Kimura,

MOA Health Science Foundation, 1-1-60

Nishi-Atami, Atami, Shizuoka 413-0038, Japan.

Tel. +81.557 .860663 - Fax. +81.557 .860665 .

E-mail: t-kimura@mhs.or.jp

Key words: complementary health practice, minimally important difference, quality of life measure, responsiveness.

Acknowledgments: we are grateful for many instructors, participants as well as staff of the MOA International to conduct this health survey.

Contributions: TK, data analysis and interpretation of data, completed this manuscript; KS, design of this survey as a chief; SU, data analysis and supported interpretation; HK, design of this survey.

Conflict of interests: the authors report no potential conflict of interests.

Received for publication: 23 March 2012. Accepted for publication: 18 May 2012.

This work is licensed under a Creative Commons Attribution NonCommercial 3.0 License (CC BYNC 3.0).

(C) Copyright T. Kimura et al., 2012

Licensee PAGEPress, Italy

Alternative Medicine Studies 2012; 2:e12

doi:10.4081/ams.2012.e12

\section{Materials and Methods}

\section{Subjects and questionnaires}

A large-scale survey of biofield therapy was conducted in Japan from February to November in 2007 to evaluate the safety and effectiveness of biofield therapy, and to analyze factors contributing to therapeutic outcomes. ${ }^{14}$ In preparation for this study, one of the authors (KS) explained the purpose of the study to approximately 100 instructors, and how they should assist participants in filling out the questionnaires. Then, the instructors explained the study's purpose and methodology to local certified therapists who acted as investigators. The investigators used an information sheet and word-of-mouth to recruit participants. The information sheet indicated that: i) participants should state the facts as they are; ii) they would receive neither special favors nor an honorarium; iii) if they declined to participate or withdraw, they would not be penalized in any way. The participants understood these explanations and signed the consent form. This study was conducted with the approval of the Institutional Review Board and the Ethics Committee of the MOA Health 
Science Foundation. Participant inclusion criteria were: individuals who were (i) able to receive biofield therapy for 30 min or longer from the investigators, (ii) able to self-evaluate the change in their symptoms, (iii) competent to answer the Japanese questionnaires, and (iv) aged 16 years or older. We included in the study those who met all the inclusion criteria and who agreed to participate without an honorarium. Participants from all over Japan completed questionnaires including both the MQL-10 and a complementary health practice questionnaire, which included food and eating, art and culture, and biofield therapy ( $n=62,056$ baseline). Of these, 10,615 participants were reexamined after 12 weeks (follow up).

Three complementary health practices were recommended to the participants. The recommendations were followed on a voluntary basis. The recommended health practice for food and eating was to eat fresh and seasonal products (organic vegetables, etc.). The art and culture recommendation was to enjoy arts, music, traditional cultures and natural beauty, etc. Biofield therapy was also recommended; this therapy is an energy therapy (untouched treatment) whose purpose is to maintain health and improve symptoms in daily life. ${ }^{15,16}$ Since these recommendations were not compulsory intervention programs, a questionnaire was used to determine the frequency or level of participants' health practices.

The MQL-10 is a likert-type questionnaire, consisting of 105 -point items related to physi- cal, mental and social wellbeing (a translation of the MQL-10 is available in the Appendix.) Each item is scored from 0 to 4 ; therefore, the range of the total score is $0-40$. Higher scores indicate better QOL. Originally, the MQL-10 was developed as an instrument for health survey to assess effects of health practices on generic Q0L, using generally worded questions. Although this instrument's name comes from the developers' organization (MOA), it is not a measure that specializes in the assessment of MOA's health programs. The validation study for this measure demonstrated that the correlation coefficient between the total score of the MQL-10 and the average score of the WHOQOL-BREF was $0.81(\mathrm{P}<0.001, \mathrm{n}=195) ; 8$ and the correlations with the general health perception, vitality, and mental health domains of the SF-36 were $0.58,0.62$, and 0.64 , respectively $(\mathrm{P}<0.001, \mathrm{n}=260)$.

\section{Statistical analysis}

We analyzed the MQL-10 scores together with the following factors: gender, age group, disease, reason for participation and complementary health practices. Of 10,615 participants, 6365 subjects $(60.0 \%)$ had complete data for all of the variables and were available for analysis. Frequency distributions of these variables are listed in Table 1.

The reliability of the MQL-10 was confirmed with Cronbach's alpha coefficient at both baseline and the follow up. The difference in the MQL-10 scores at baseline for each of the fac- tors was analyzed with Mann-Whitney U Test for gender and disease; and with analysis of variance and Tukey's HSD test for factors with more than 2 levels: age group had 8 levels; reason for participation had 5 categories; and complementary health practices had 5 levels. Effect size (ES) was calculated by dividing difference between means by the standard deviation (SD). Statistically, ES value of 0.2 is small; of 0.5 is medium; and 0.8 is large. 17

Second, the difference in the change of the MQL-10 scores between baseline and follow up (during 12 weeks) for each of the factors was analyzed in the same way. ES was calculated by dividing the difference between the means of the change scores by the SD of baseline score. Furthermore, standardized response mean (SRM) was calculated by dividing the difference between the mean of the change scores by the SD of change.

Third, the subjects were divided into 3 groups: increase, no change, and decrease in the frequency of each complementary health practice. The changes in the MQL-10 scores were compared among the 3 groups.

Finally, the MID of the MQL-10 was determined by using a distribution-based approach. The MID was obtained as an integer value larger than half of both SDs of the baseline score and the change between the baseline and follow-up scores.

Statistical significance was set at $\mathrm{P}<0.05$. These statistical analyses were conducted using SPSS for Windows, version 13.0.18

Table 1. Frequency distribution of factors in the baseline for analysis $(n=6365)$.

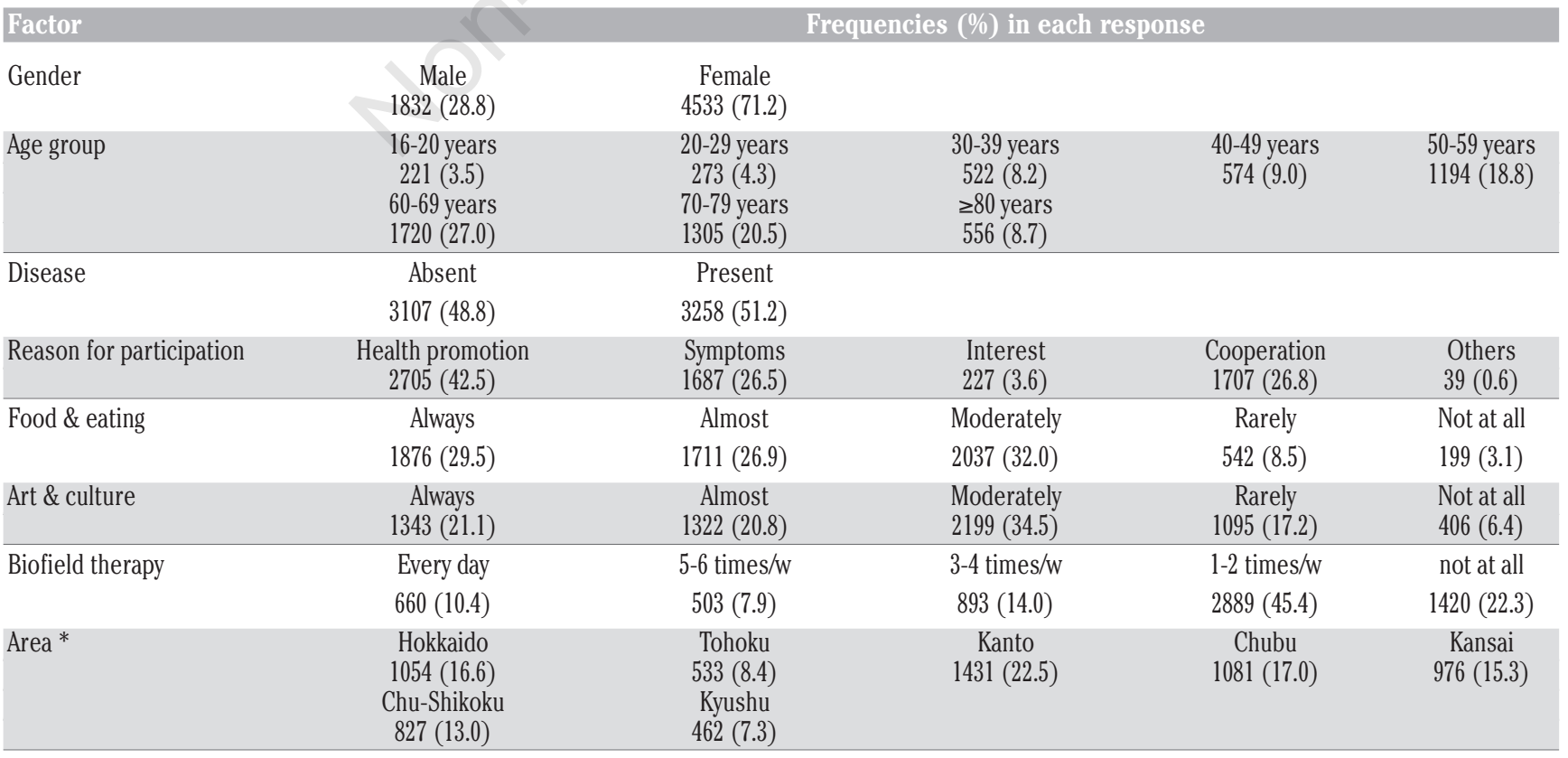

*This factor was not used for analysis. Japan was divided into seven areas. Tokyo was contained within Kanto, and Osaka and Kyoto within Kansai. 


\section{Results}

This dataset for analysis included more females (71.2\%) than males, most of whom were over 50 years of age (Table 1). The mean baseline MQL-10 score was $26.4 \pm 5.83 \mathrm{SD}$ and the mean follow-up score was 27.6 \pm 5.45 SD. The mean change score between baseline and follow up was $1.20 \pm 4.41 \mathrm{SD}$. The ES for change was 0.21 and the SRM was 0.27. Cronbach's alpha coefficient of MQL-10 was 0.872 at the baseline and 0.879 at follow up.

The differences in the MQL-10 scores at baseline for factors are shown in Table 2 . The MQL-10 scores were significantly related to gender, age group, disease, reason for participation and complementary health practices. The ES between the highest and lowest categories reached approximately 0.8 in food and eating and art and culture among the complementary health practices. Although consider-

Table 2. Differences of the MQL-10 scores in the baseline for factors.

\begin{tabular}{|c|c|c|c|c|c|}
\hline Factor & Category* & Mean & Difference & Significance & Effect size \\
\hline Gender & $\begin{array}{l}\text { Male } \\
\text { Female }\end{array}$ & $\begin{array}{l}26.89 \\
26.24\end{array}$ & 0.65 & $<0.001$ & 0.111 \\
\hline Age group & $\begin{array}{l}20-29 \text { years } \\
70-79 \text { years }\end{array}$ & $\begin{array}{l}24.36 \\
27.28\end{array}$ & 2.92 & $<0.001$ & 0.501 \\
\hline Disease & $\begin{array}{l}\text { Absent } \\
\text { Present }\end{array}$ & $\begin{array}{l}27.89 \\
25.03\end{array}$ & 2.86 & $<0.001$ & 0.491 \\
\hline $\begin{array}{l}\text { Reason for } H \\
\text { partecipations }\end{array}$ & $\begin{array}{l}\text { Health promotion } \\
\text { Symptoms }\end{array}$ & $\begin{array}{l}27.84 \\
24.19\end{array}$ & 3.65 & $<0.001$ & 0.626 \\
\hline Food \& eating & $\begin{array}{l}\text { Always } \\
\text { Rarely }\end{array}$ & $\begin{array}{l}28.10 \\
23.46\end{array}$ & 4.64 & $<0.001$ & 0.796 \\
\hline Art \& culture & $\begin{array}{l}\text { Always } \\
\text { Not at all }\end{array}$ & $\begin{array}{l}28.50 \\
23.67\end{array}$ & 4.83 & $<0.001$ & 0.828 \\
\hline Biofield therapy & $\begin{array}{l}\text { Every day } \\
\text { Not at all }\end{array}$ & $\begin{array}{l}27.00 \\
26.02\end{array}$ & 0.98 & $<0.001$ & 0.168 \\
\hline
\end{tabular}

* In case of more than 2 categories, the highest and lowest means are shown.

Table 3. Differences of the changes of the MQL-10 scores between baseline and the 12week follow-up for factors.

\begin{tabular}{|c|c|c|c|c|c|c|}
\hline Factor & Category* & Mean & Difference & Significance & Effect size & SRM \\
\hline Gender & $\begin{array}{l}\text { Male } \\
\text { Female }\end{array}$ & $\begin{array}{l}1.27 \\
1.17\end{array}$ & 0.10 & ns & & \\
\hline Age group & $\begin{array}{l}20-29 \text { years } \\
70-79 \text { years }\end{array}$ & $\begin{array}{l}1.97 \\
0.86\end{array}$ & 1.11 & $<0.001$ & 0.190 & 0.252 \\
\hline Disease & $\begin{array}{l}\text { Absent } \\
\text { Present }\end{array}$ & $\begin{array}{l}0.98 \\
1.41\end{array}$ & 0.43 & 0.005 & 0.074 & 0.098 \\
\hline $\begin{array}{l}\text { Reason for } \\
\text { participation }\end{array}$ & $\begin{array}{l}\text { Health promotion } \\
\text { Interest }\end{array}$ & $\begin{array}{l}0.91 \\
1.89\end{array}$ & 0.98 & $<0.001$ & 0.168 & 0.222 \\
\hline Food \& eating & $\begin{array}{l}\text { Always } \\
\text { Rarely }\end{array}$ & $\begin{array}{l}0.77 \\
2.14\end{array}$ & 1.37 & $<0.001$ & 0.235 & 0.311 \\
\hline Art \& culture & $\begin{array}{l}\text { Always } \\
\text { Not at all }\end{array}$ & $\begin{array}{l}0.53 \\
1.90\end{array}$ & 1.43 & $<0.001$ & 0.245 & 0.324 \\
\hline $\begin{array}{l}\text { Biofield } \\
\text { therapy }\end{array}$ & $\begin{array}{l}\text { Every day } \\
\text { Not at all }\end{array}$ & $\begin{array}{l}0.85 \\
1.73\end{array}$ & 0.88 & $<0.001$ & 0.151 & 0.200 \\
\hline
\end{tabular}

*In case of more than 2 categories, the highest and lowest means are shown. SRM, standardized response mean.

Table 4. Differences of the changes of the MQL-10 scores for the frequencies of complementary health practices.

\begin{tabular}{|c|c|c|c|c|c|c|}
\hline Factor & Category* & Mean & Difference & Significance & Effect size & SRM \\
\hline Food \& eating & $\begin{array}{l}\text { Increase } \\
\text { Decrease }\end{array}$ & $\begin{array}{l}2.23 \\
0.49\end{array}$ & 1.74 & $<0.001$ & 0.298 & 0.395 \\
\hline Art \& culture & $\begin{array}{l}\text { Increase } \\
\text { Decrease }\end{array}$ & $\begin{array}{l}2.09 \\
0.45\end{array}$ & 1.64 & $<0.001$ & 0.281 & 0.372 \\
\hline $\begin{array}{l}\text { Biofield } \\
\text { therapy }\end{array}$ & $\begin{array}{l}\text { Increase } \\
\text { Decrease }\end{array}$ & $\begin{array}{l}1.47 \\
0.87\end{array}$ & 0.60 & 0.002 & 0.103 & 0.136 \\
\hline
\end{tabular}

*The increase and decrease of frequencies between baseline and follow-up are shown. SRM, standardized response mean.

able differences among age groups were observed, gender difference was small. Participants without illness had higher scores than those who had present illness (ES=0.491). Those who participated to promote their health had higher scores than those who expected symptomatic improvement $(\mathrm{ES}=0.626)$

The differences in the changes of the MQL10 scores between baseline and the 12 -week follow up according to factors are shown in Table 3. The change scores were related to age group, disease, reason for participation and complementary health practices. The difference in the change scores as a function of age group, disease and reason for participation were small $(\mathrm{ES}=0.074-0.19 ; \quad \mathrm{SRM}=0.098$ $0.252)$. The change scores in the complementary health practices were significant but not large (ES=0.151-0.245; SRM=0.2-0.324).

The differences in the changes of the MQL10 scores for the frequencies of complementary health practices are shown in Table 4 and Figure 1. The scores of participants who
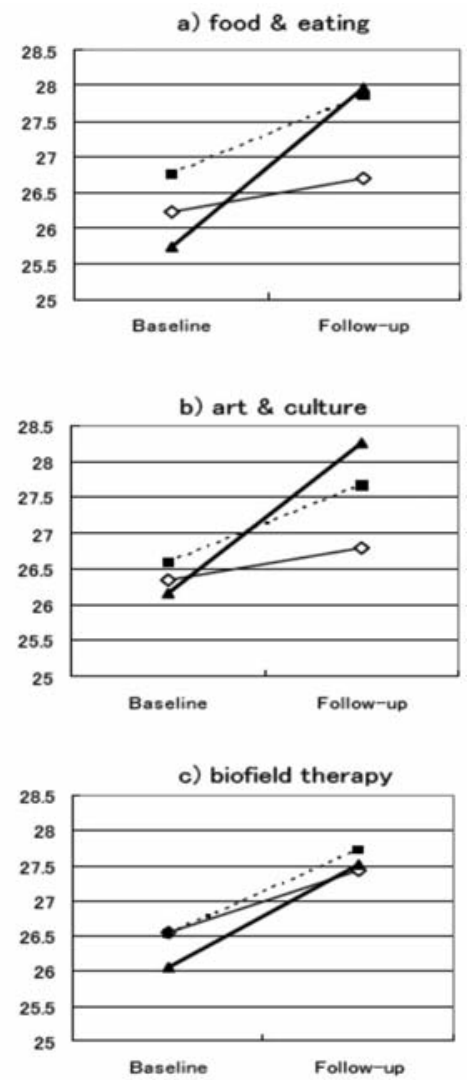

Figure 1. Changes of quality of life related to the frequencies of complementary health practices: a) food and eating, b) art and culture, and c) biofield therapy. Quality of life was measured with the 10item Mokichi Okada Association quality of life questionnaire. 
increased the frequencies of health practices were significantly elevated compared to those who decreased them. The changes in food and eating and art and culture were larger than in biofield therapy.

The MID of the MQL-10 determined by using a distribution-based approach was 3 points, for the 1/2 SD of the baseline score was 2.9, and that of the change was 2.2. Cross tabulations of the relationships between change of the MQL10 score and changes in the complementary health practices are shown in Table 5 . These relationships were significant with $\chi^{2}$ test. There were comparatively higher percentages of participants whose scores of the MQL-10 increased 3 points and more in the increase groups of the complementary health practices.

\section{Discussion}

This study found that: i) the MQL-10 was reliable; ii) it was useful for comparisons between categories; iii) its changes in repeated measurement were detectable; and iv) its MID was determined. Participants with present illness had lower scores of the MQL-10. This also demonstrated the validity of this instrument.

There were significant and definite associations of the MQL-10 scores at baseline with complementary health practices. The changes in scores between baseline and follow up were also significantly associated with the complementary health practices, but these associations were not strong. These results suggest that the participants who exhibited a high frequency of health practices had considerably higher MQL-10 scores at baseline and, therefore, due to a ceiling effect, could not have even higher scores in the follow up. In contrast, the participants with increasing frequencies of health practices improved their QOL. Since they did not practice very frequently and had considerably low MQL-10 scores at baseline, the scores were not restricted and could show an increase. Among the health practices, the change scores related to biofield therapy were small. Food and eating, and art and culture programs were often conducted to promote health status and prevent illness. In contrast, biofield therapy was expected to improve symptoms and cure illness; therefore, the participants with present illnesses tended to practice it frequently and had lower scores on the MQL-10.

The MQL-10 inquires about a respondent's QOL during the previous one month (about 4 weeks). This instrument could not cover the participants' QOL between baseline and follow up during the 12 weeks. The change in the MQL-10 scores indicated variation in the QOL between two periods; however, we could not

Table 5. Cross tabulations of change of the MQL-10 score by change of the complementary health practices.

\begin{tabular}{llrrrr}
$\begin{array}{l}\text { Complementary } \\
\text { health practice }\end{array}$ & \multicolumn{4}{c}{ MQL-10 score* } \\
& Total & $\begin{array}{c}\text { Decrease } \\
\text { 1008 (15.8\%) }\end{array}$ & $\begin{array}{r}\text { No change } \\
3202(50.3 \%)\end{array}$ & $\begin{array}{c}\text { Increase } \\
\text { Food \& eating }\end{array}$ & \multicolumn{1}{c}{ Total } \\
& Decrease & $297(20.5 \%)$ & $742(51.2 \%)$ & $410(28.3 \%)$ & $1449(100 \%)$ \\
& No change & $547(15.2 \%)$ & $1873(52.1 \%)$ & $1175(32.7 \%)$ & $3595(100 \%)$ \\
& Increase & $164(12.4 \%)$ & $587(44.4 \%)$ & $570(43.2 \%)$ & $1321(100 \%)$ \\
\multirow{2}{*}{ Art \& culture } & Decrease & $296(21.4 \%)$ & $697(50.4 \%)$ & $390(28.2 \%)$ & $1383(100 \%)$ \\
& No change & $518(15.3 \%)$ & $1769(52.2 \%)$ & $1105(32.6 \%)$ & $3392(100 \%)$ \\
& Increase & $194(12.2 \%)$ & $736(46.3 \%)$ & $660(41.5 \%)$ & $1590(100 \%)$ \\
\hline \multirow{2}{*}{ Biofield therapy } & Decrease & $216(18.4 \%)$ & $583(49.6 \%)$ & $376(32.0 \%)$ & $1175(100 \%)$ \\
& No change & $571(14.9 \%)$ & $1989(51.9 \%)$ & $1273(33.2 \%)$ & $3833(100 \%)$ \\
& Increase & $221(16.3 \%)$ & $630(46.4 \%)$ & $506(37.3 \%)$ & $1357(100 \%)$ \\
\hline
\end{tabular}

*Increase of the MQL score means 3 points more than in the baseline, whereas decrease of the MQL-10 score means 3 points less than in the baseline. All the relationships between change of the 10-item Mokichi Okada Association quality of life questionnaire score and the health practice were significant with $\chi^{2}$ test $(\mathrm{P}<0.001)$. MQL-10, 10-item Mokichi Okada Association quality of life questionnaire.

identify exactly when these QOL changes occurred. It is possible that U-shape changes that we could not assess may have occurred. Additionally, these interpretations were described based on the total score of MQL-10. Neither subscales nor individual items of the MQL-10 were analyzed and discussed. Responsiveness was assumed to vary among the items. For example, Item \#4 of the MQL-10 inquires about living environment, which is considered to be important for generic QOL, but not to be suited to a prospective study for health practice. Further studies should be conducted on the responsiveness of individual items of the MQL-10 as well as on the interval to measure.

The responsiveness of the MQL-10 was demonstrated with ES and SRM. Since the SD of the MQL-10 scores was larger than that of change, the ES was smaller than the SRM. The estimated MID of the MQL-10, in which scores vary from 0 to 40 , was 3 points. The difference in the mean scores between the increase and decrease categories of the complementary health practices were less than the MID, and were not very remarkable (ES=0.103-0.298; $\mathrm{SRM}=0.136-0.395$; Table 4). The results of cross tabulations of change of the MQL-10 score by changes of the practices were considerably more convincing (Table 5). There were higher rates of participants who had 3 points and more scores in the follow up in the increase groups of the complementary health practices, especially food and eating and art and culture. In other words, there were comparatively higher rates of participants who practiced the programs more frequently in the follow up than at baseline among the participants whose scores increased 3 points and more. These results suggest that the health practices may have improved the QOL of the participants. Cella, Eton and their colleagues reported on the MID of the Functional
Assessment of Cancer Therapy and calculated $1 / 3$ and $1 / 2$ of SDs as a distribution-based approach. ${ }^{11,12}$ The more severe criteria used in this study were considered to have demonstrated the reliability of the result. Revicki $e t$ al. ${ }^{19}$ reviewed methods for MID and recommended an anchor-based approach. One difficulty is that changes in general QOL, as assessed by the MQL-10, were not directly estimated by patients or clinicians; therefore, the MID of this instrument could only be established with a distribution-based approach.

\section{Conclusions}

This study has several limitations. One is that random sampling was not used. Although the participants were distributed throughout Japan, the ratio of samples by area did not correspond to the population distribution (Table 1). Second, the gender and age of the participants were biased. Generally, middle-aged and older women have health concerns and can afford to participate in a survey like this. Third, the ratio of members who were interested in the health practices and had experienced them was considerably over-represented. However, analysis for the group of non-members indicated similar results (data not shown). Comparison with a control group could make the impact clearer, but the Ethics Committee did not approve the protocol for a control group that would have discouraged the participants from practicing health programs. Fourth, the socioeconomic status of the participants such as annual income, educational level, and occupation was not examined; thus, the results could not be adjusted for these variables. Fifth, we did not collect personal data about the instructors and certified therapists who cooperated with us in this survey; thus, the impact 
of differences in their experience and abilities could not be determined. Regardless of these limitations, we consider this study to have demonstrated the relationship between health practices and QOL in Japanese adults.

The results of this study suggest that the MQL-10 is useful for assessing the effects of complementary health practices on QOL. The estimate of 3 points for the MID of the MQL-10 using a distribution-based approach was considered reasonable. The MQL-10 items are related to general health or generic QOL perceptions, and its reliability, validity and responsiveness have been confirmed. Based on these findings, the MQL-10 can be considered to be acceptable for general use.

\section{References}

1. Balloc NB, Breslow L. Relationship of physical health status and health practices. Prev Med 1972;1:409-21.

2. MOA International Corporation. Introduction: MOA - Working toward creating a new civilization. Available from: http://www.moainternational.or.jp/en/intro /intro1.html. Accessed on: May 17, 2012.

3. Hatayama M, Suzuki K, Ishida A, et al. Long-term efficacy of Okada purifying therapy (bio-energy healing) on menopausal symptoms. Res Rep MOA Health Sci 2009;12:5-12.

4. Bruti G, Ramos M. Okada purifying therapy in refractory migraine: a pilot study. Res Rep MOA Health Sci 2010;14:5-15.
5. Uchida S, Iha T, Yamaoka K, et al. Effect of biofield therapy in the human brain. $\mathrm{J}$ Altern Complement Med 2012 (in press).

6. Management of Substance Abuse, World Health Organization. WHO Quality of LifeBREF (WHOQOL-BREF). Available from: http://www.who.int/substance_abuse/rese arch_tools/whoqolbref/en/ Accessed on: May 17, 2012.

7. Ware JE, Sherbourne C. The MOS 36-item short-form health survey (SF-36): I. conceptual framework and item selection. Med Care 1992;30:473-83.

8. Kimura T, Suzuki K, Morioka H, et al. Development and validation of the 10 -Item MOA Quality of Life Questionnaire (MQL10) for large-scale health survey. Res Rep MOA Health Sci 2009;13:73-84. [Article in Japanese].

9. Jaeschke R, Singer J, Guyatt GH. Measurement of health status. Ascertaining the minimal clinically important difference. Control Clin Trials 1989;10:407-15.

10. Redelmeier DA, Guyatt GH, Goldstein RS. Assessing the minimal important difference in symptoms: a comparison of two techniques. J Clin Epidemiol 1996;49: 1215-9.

11. Cella D, Eton DT, Fairclough DL, et al. What is a clinically meaningful change on the functional assessment of cancer therapy-lung (FACT-L) questionnaire? Results from Eastern cooperative oncology group (ECOG) study 5592. J Clin Epidemiol 2002;55:285-95.

12. Eton DT, Cella D, Yost KJ, et al. A combination of distribution- and anchor-based approaches determined minimally important differences (MIDs) for four endpoints in a breast cancer scale. J Clin Epidemiol 2004;57:898-910.

13. Coeytaux RR, Kaufman JS, Chao R, et al. Four methods of estimating the minimal important difference score were compared to establish a clinically significant change in headache impact test. J Clin Epidemiol 2006;59:374-80.

14. Suzuki K, Uchida S, Kimura T, Katamura H. A large cross-sectional descriptive study of self-reports after biofield therapy in Japan: Demography, symptomatology, and circumstances of treatment administration. Altern Ther Health Med 2012;18:3550.

15. MOA International Corporation. Okada Health and Wellness Program. Available from: http://www.moainternational. or.jp/ en/health/therapy.html. Accessed on: May 17, 2012.

16. Weil A. Secular spirituality and emotional well-being. In: Spontaneous happiness. New York: Little, Brown and Company; 2011. pp. 167-194.

17. Cohen J. A power primer. Psychol Bull 1992;112:155-9.

18. SPSS Inc. SPSS 13.0J Brief Guide. Chicago: SPSS Incorporated; 2004.

19. Revicki D, Hays RD, Cella D, Sloan J. Recommended methods for determining responsiveness and minimally important differences for patient-reported outcomes. J Clin Epidemiol 2008;61:102-9. 